\title{
Letter to editor: Incorrect identification of study species
}

\author{
Mahmood Soofi $^{1} \cdot$ Arash Ghoddousi $^{1,2} \cdot$ Lukas Egli $^{1} \cdot$ Igor Khorozyan $^{1} \cdot$ \\ Matthias Waltert ${ }^{1}$
}

Received: 31 October 2016 / Accepted: 2 November 2016/Published online: 24 November 2016

(C) Springer-Verlag London 2016

Dear Editor,

Mirzakhani et al. (2016) presented the first confirmed case of the feline panleukopenia virus (FPL) in wildcat (Felis silvestris) in Iran using a polymerase chain reaction (PCR) technique. In principle, identification of such a contagious virus in captive conditions may surely expand our understanding of potential infections in captive and wild-ranging felid populations. Knowing valid scientific names of studied specimens in such studies is essential to trace host-vector relationships and disease trends. Mirzakhani et al. (2016) misidentified the 2-year-old specimen from Urmia Zoo that they examined during their study as the wildcat. Indeed, judging from Fig. 1 on the second page of Mirzakhani et al. (2016), this specimen is the jungle cat (Felis chaus).

While wildcats (Fig. 1) may be confused with domestic or feral cats (Reig et al. 2001), distinguishing wildcats from jungle cats is relatively easy. Jungle cats are larger, have longer limbs and a shorter tail than wildcats (Firouz 2005). The wildcat's fur varies from tawny grey to light grey or sand coloured, showing pronounced stripes and spots on the flanks, head and limbs, and also distinct rings on the black-tipped tail (Firouz 2005). In most of the Middle East, including Iran, the Asiatic wildcat (Felis silvestris ornata) has spots on its flanks and head, while the coat of the jungle cat is uniformly sandy brown or greyish, without spots. The only markings of the jungle cat are vague stripes on its legs and less distinct rings on the tail (Firouz 2005, Gray et al. 2016). The other noticeable differences of the jungle cat are the black-tipped and slightly tufted ears, long limbs and a shorter tail (Firouz 2005; Yamaguchi et al. 2004; Yamaguchi et al. 2015). The jungle cat is heavier than the wildcat $(3-8 \mathrm{~kg}$ and $2.5-$ $5 \mathrm{~kg}$, respectively) (Gray et al. 2016).

Mahmood Soofi

Mahmood.Soofi@stud.uni-goettingen.de

1 Workgroup on Endangered Species, J.F. Blumenbach Institute of Zoology and Anthropology, Georg-August-Universität Göttingen, Bürgerstrasse 50, 37073 Göttingen, Germany

2 Conservation Biogeography Lab, Geography Department, Humboldt-Universität zu Berlin, Under den Linden 6, 10099 Berlin, Germany 
Fig. 1. A camera-trapped Asiatic wildcat (Felis silvestris ornata) in Golestan National Park, Iran (left), and a jungle cat (Felis chaus) in Arevik National Park, Armenia (right). Note different overall shape, coating pattern and tail length. Credits: Persian Wildlife Heritage Foundation (wildcat), I. Khorozyan/A. Malkhasyan (jungle cat)
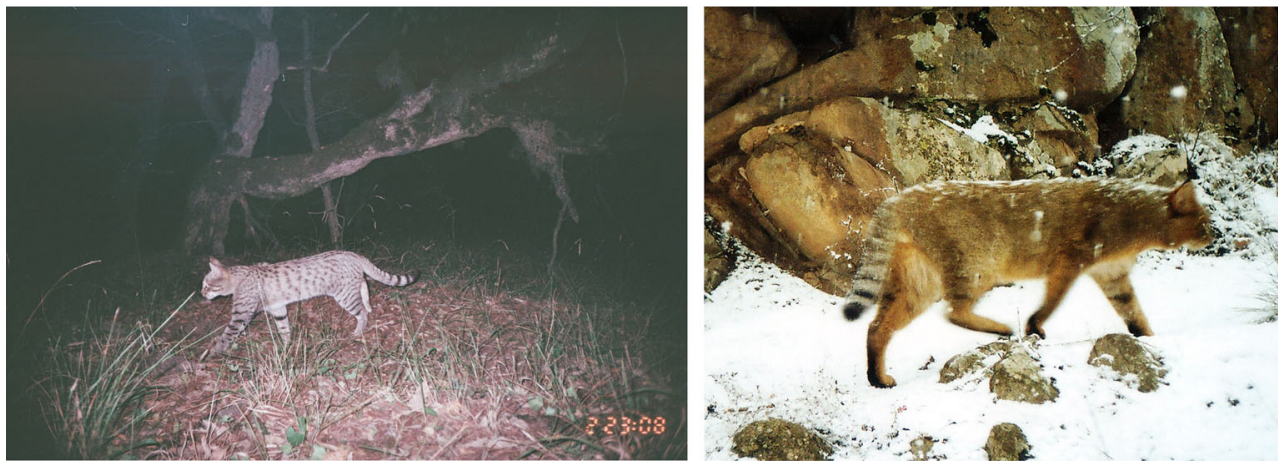

Unfortunately, Mirzakhani et al. (2016) do not describe the origin, sex and morphometric measurements of the studied specimen, which would definitely be a valuable contribution to species biology and ecology. We appreciate the authors' study and do not intend to criticize its results, understanding that taxonomy is not a priority for comparative clinical pathology. However, correct identification of studied species is biologically important.

Conflict of interest Funding was provided by Erasmus Mundus SALAM2 (M.S), Humboldt-Universität zu Berlin (A.G) and GeorgAugust-Universität Göttingen (L.E, I.K and M.W).

Ethical approval No animals were handled during this study.

\section{References}

Firouz E (2005) The complete fauna of Iran. Tauris, London

Gray TNE, Timmins RJ, Jathana D, Duckworth JW, Baral H, Mukherjee S (2016) Felis chaus, The IUCN Red List of Threatened Species. e.T8540A50651463. Assessed 25 October 2016

Mirzakhani N, Tehrani AA, Yousefi A, Morvaridi A, Kian M (2016) A case of feline panleukopenia in Felis silvestris in Iran; confirmed by PCR. Comp Clin Pathol. doi:10.1007/s00580-016-2322-1

Reig S, Daniels MJ, Macdonald DW (2001) Craniometric differentiation within wild living cats in Scotland using 3D morphometrics. J Zool Lond 253:121-132

Yamaguchi N, Driscoll CA, Kitchener AC, Ward JM, Macdonald DW (2004) Craniological differentiation between European wildcats (Felis silvestris silvestris), African wildcats ( $F$. s. lybica) and Asian wildcats (F. s. ornata): implications for their evolution and conservation. Biol J Linn Soc 83:47-63

Yamaguchi N, Kitchener A, Driscoll C, Nussberger B (2015) Felis silvestris. The IUCN Red List of Threatened Species. e.T60354712A50652361. Assessed 25 October 2016 